\title{
Autophagy is essential for optimal translocation of iron to seeds in Arabidopsis
}

\author{
Mathieu Pottier ${ }^{1, *, \oplus}$, Jean Dumont ${ }^{2}$, Céline Masclaux-Daubresse ${ }^{3, \oplus}$ and Sébastien Thomine ${ }^{1, t, \oplus}$ \\ ${ }^{1}$ Institut de Biologie Intégrative de la Cellule (I2BC), CEA, CNRS, Université Paris-Sud, Université Paris-Saclay, Avenue de la Terrasse, \\ 91198 Gif-sur-Yvette, France \\ 2 UT2A, Hélioparc Pau Pyrénées, 2, avenue du président Angot, 64053 Pau, France \\ ${ }^{3}$ Institut Jean-Pierre Bourgin, INRA, AgroParisTech, CNRS, Université Paris-Saclay, 78000, Versailles, France \\ *Present address: InBioS, PhytoSYSTEMS, Laboratory of Plant Physiology, University of Liège, Sart Tilman Campus Quartier Vallée 1, \\ Chemin de la Vallée 4, B-4000, Liège, Belgium. \\ † Correspondence: sebastien.thomine@i2bc.paris-saclay.fr
}

Received 17 May 2018; Editorial decision 23 October 2018; Accepted 2 November 2018

Editor: Christine Foyer, Leeds University, UK

\begin{abstract}
Micronutrient deficiencies affect a large part of the world's population. These deficiencies are mostly due to the consumption of grains with insufficient content of iron $(\mathrm{Fe})$ or zinc $(\mathrm{Zn})$. Both de novo uptake by roots and recycling from leaves may provide seeds with nutrients. Autophagy, which is a conserved mechanism for nutrient recycling in eukaryotes, was shown to be involved in nitrogen remobilization to seeds. Here, we have investigated the role of this mechanism in micronutrient translocation to seeds. We found that Arabidopsis thaliana plants impaired in autophagy display defects in nutrient remobilization to seeds. In the atg5-1 mutant, which is completely defective in autophagy, the efficiency of Fe translocation from vegetative organs to seeds was severely decreased even when Fe was provided during seed formation. Combining atg5-1 with the sid2 mutation that counteracts premature senescence associated with autophagy deficiency and using ${ }^{57} \mathrm{Fe}$ pulse labeling, we propose a two-step mechanism in which Fe taken up de novo during seed formation is first accumulated in vegetative organs and subsequently remobilized to seeds. Finally, we show that translocation of $\mathrm{Zn}$ and manganese $(\mathrm{Mn})$ to seeds is also dependent on autophagy. Fine-tuning autophagy during seed formation opens up new possibilities to improve micronutrient remobilization to seeds.
\end{abstract}

Keywords: ${ }^{57} \mathrm{Fe}$, iron loading, iron recycling, leaf senescence, metal, micronutrient, remobilization, premature senescence.

\section{Introduction}

Metal micronutrients are essential to all forms of life. For instance, iron $(\mathrm{Fe})$ plays a major role in oxido-reduction reactions allowing respiration in mitochondria and photosynthesis in chloroplasts (Nouet et al., 2011). Worldwide, 2 billion people suffer from $\mathrm{Fe}$ deficiency which affects mostly children and women in developing countries (WHO, 2016). Staple food crops are poor sources of $\mathrm{Fe}$, and the major place of these crops in the human diet is one of the leading causes of $\mathrm{Fe}$ deficiency (Murgia et al., 2012). During the last decade, different biofortification strategies such as fertilization, conventional breeding, and genetic engineering were pursued in an attempt to increase key micronutrient levels in seeds of crop species (Murgia et al., 2012).

The improvement of micronutrient loading in seeds requires knowledge of micronutrient trafficking pathways within the plant, including uptake from soil and remobilization from 
senescing organs. To date, most studies on micronutrients have focused on their uptake in root cells, intracellular partitioning, and long-distance transport. Several proteins participate in the mandatory solubilization and reduction of $\mathrm{Fe}^{3+}$ to $\mathrm{Fe}^{2+}$ prior to its uptake by a plasma membrane transporter, AtIRT1, in the epidermis of Arabidopsis roots (Robinson et al., 1999; Vert et al., 2002; Santi and Schmidt, 2009; Fourcroy et al., 2014; Lefevre et al., 2018). Fe is transported to the shoot upon loading in the xylem (Durrett et al., 2007; Morrissey et al., 2009), and translocation to sink tissues is mediated by loading/unloading in the phloem after Fe chelation to nicotianamine (Schuler et al., 2012). Finally, the oligopeptide transporter 3 (AtOPT3) could transport chelated Fe to ensure Fe loading to seeds (Stacey et al., 2008). During vegetative growth, Fe is mostly directed towards photosynthetic tissues. $\mathrm{Fe}$ is crucial for photosynthesis, and $>80 \%$ of the $\mathrm{Fe}$ in mesophyll cells is concentrated in chloroplasts (Shingles et al., 2002). Thus, photosynthetic tissues constitute a large Fe pool potentially available for remobilization during seed filling. However, the mechanisms of micronutrient remobilization from vegetative organs during senescence have received little attention to date (Pottier et al., 2014). Senescence in Arabidopsis thaliana is associated with a decrease by $50 \%$ of leaf $\mathrm{Fe}$ concentration, in parallel with micronutrient filling in seeds (Himelblau and Amasino, 2001). This finding implies that $50 \%$ of the micronutrients present in senescent leaves are not remobilized. A better understanding of micronutrient remobilization from senescent organs is therefore likely to highlight new solutions to improve seed micronutrient content. More specifically, mechanisms controlling the availability of nutrients in source organs, such as autophagy, could be a matter of great significance for micronutrient loading in seeds (Shi et al., 2012; Pottier et al., 2014).

Autophagy is conserved from yeast to animals and plants. It allows degradation of cytoplasmic components by lysosomal (animals) or vacuolar (plants) internalization mediated by double membrane vesicles called autophagosomes (Reumann et al., 2010). Autophagy promotes energy production, elimination of toxic components, and nutrient recycling by discarding aberrant proteins, damaged organelles, as well as normal cytoplasmic components when they are no longer useful (Yoshimoto, 2012). Autophagy-related genes (ATG genes) involved in autophagosome formation were first identified in yeast (Matsuura et al.,1997). Subsequently, orthologues of ATG genes were identified in plants, and autophagy-deficient plants were characterized (Li and Vierstra, 2012). All autophagy-deficient plants exhibit hypersensitivity to carbon and nitrogen starvation, pointing to a central role for autophagy in nutrient recycling (Liu and Bassham, 2012; Guiboileau et al., 2013). The up-regulation of $A T G$ genes during leaf senescence in Arabidopsis suggests a role for autophagy in nutrient recycling at the end of the plant life cycle (Doelling et al., 2002; van der Graaff et al., 2006; Chung et al., 2010; Breeze et al., 2011; Liu and Bassham, 2012). In agreement with this hypothesis, nitrogen remobilization efficiency (i.e. the proportion of nitrogen allocated to seeds through remobilization from vegetative tissues during senescence) is strongly affected in autophagydeficient plants (Guiboileau et al., 2012).

In this work, we investigated the role of autophagy in metal micronutrient resorption from senescent vegetative organs to seeds in Arabidopsis. Our results indicate that micronutrient remobilization is impaired in vegetative tissues of autophagydeficient plants. Focusing on ATG5, which is essential for autophagosome formation (Kirisako et al., 2000), we show that autophagy-dependent remobilization is critical for optimal translocation of $\mathrm{Fe}$ as well as other metal nutrients from vegetative organs to seeds.

\section{Materials and methods}

\section{Plant material and growth conditions}

Arabidopsis thaliana (L.) ecotype Columbia-0 (Col-0) [atg5-1 (SALK_020601), atg9-2 (SALK_130796), AtATG18a RNAi (RNAi18), sid2, atg 5 sid2], and ecotype Wassilewskija (WS) [atg4 (atg4a4b-1), atg9-1] have been described previously (Hanaoka et al., 2002; Yoshimoto et al., 2004, 2009; Xiong et al., 2005; Inoue et al., 2006).

The first experiment (experiment 1) including all autophagy-deficient plants presented in this study was conducted on sand. Seeds were sown on sand, and plants were watered three times per week for $2 \mathrm{~h}$ with high nitrogen nutritive solution as described in Chardon et al. (2010). Plants were grown under the following conditions: $8 / 16 \mathrm{~h}, 21 / 17^{\circ} \mathrm{C}$ light/dark until 56 days after sowing (DAS), and then transferred to long days (16 h light), maintaining similar day/night temperatures. When plants were dry, seeds were separated from the dry remains of vegetative tissues, including leaves, stems, and siliques, to determine their respective dry weights and metal contents.

In other experiments (experiments 2 and 3 ) performed to determine the involvement of autophagy in Fe remobilization, plants were cultivated on a 1/1 mix of sand and perlite, and watered three times per week for $2 \mathrm{~h}$ with modified Hoagland solution $\left[0.28 \mathrm{mM} \mathrm{KH}_{2} \mathrm{PO}_{4}, 1.25 \mathrm{mM} \mathrm{KNO}_{3}\right.$, $0.75 \mathrm{mM} \mathrm{MgSO} 4,1.5 \mathrm{mM} \mathrm{Ca}\left(\mathrm{NO}_{3}\right), 25 \mu \mathrm{M} \mathrm{H}_{3} \mathrm{BO}_{3}, 50 \mu \mathrm{M} \mathrm{KCl}, 1 \mu \mathrm{M}$ $\mathrm{ZnSO}_{4}, 0.1 \mu \mathrm{M} \mathrm{Na} \mathrm{MoO}_{4}, 0.5 \mu \mathrm{M} \mathrm{CuSO}_{4}, 5 \mu \mathrm{M} \mathrm{MnSO}$, and $3 \mathrm{mM}$ MES-KOH, pH 5.7]. Fe $(10 \mu \mathrm{M})$ was provided as $\mathrm{Fe}^{3+}$ chelated to HBED $\left[N, N^{\prime}\right.$-di(2-hydroxybenzyl) ethylene diamine- $N, N^{\prime}$-diacetic acid monochloride hydrate; Strem Chemicals, Newburyport, MA, USA] prepared as described by Lanquar et al. (2005). Plants were grown in a climate chamber under the following conditions: $75 \%$ relative humidity, $9 / 15 \mathrm{~h}$, $21 / 19^{\circ} \mathrm{C}$ light/dark until 68 DAS. Then, plants were transferred to long days (16 h light), maintaining similar conditions. At the onset of flowering (78 DAS), half of the plants were maintained in Fe-sufficient nutrition (solution containing $10 \mu \mathrm{M}$ Fe-HBED) and the other half were transferred to Fe deprivation nutrition (solution containing $20 \mu \mathrm{M}$ ferrozine) until the end of the plant life cycle. When plants were dry, leaves, seeds, and stems including empty siliques were harvested separately to determine their dry weight and their metal content. In experiment 2, light was enriched in blue and red wavelengths (OSRAM FLUORA, Munich, Germany) and light intensity was maintained to $100 \mu \mathrm{mol}$ photons $\mathrm{m}^{-2} \mathrm{~s}^{-1}$. In experiment 3, which is presented in the Supplementary figures, white light was provided by TLD 58W 830 and 840 (Philips, Amsterdam, The Netherlands) with an intensity of $230 \mu \mathrm{mol}$ photons $\mathrm{m}^{-2} \mathrm{~s}^{-1}$.

\section{Metal concentration analysis}

After weight measurement, dried samples were digested in $2 \mathrm{ml}$ of $70 \%$ nitric acid in a DigiBlock ED36 (LabTech, Italy) at $100{ }^{\circ} \mathrm{C}$ for $1 \mathrm{~h}$, $120^{\circ} \mathrm{C}$ for $6 \mathrm{~h}$, and $80^{\circ} \mathrm{C}$ for $1 \mathrm{~h}$. After dilution in trace-metal-free water, the metal content of the samples was determined by atomic absorption spectrometry using an AA240FS flame spectrometer or with an MP AES 4200 Atomic Emission spectrometer (Agilent, USA).

\section{${ }^{57} \mathrm{Fe}$ labeling}

For ${ }^{57} \mathrm{Fe}$ labeling, ${ }^{57} \mathrm{Fe}^{3+}$ (96.28 atom \%) was prepared and combined with HBED to replace ${ }^{56} \mathrm{FeHBED}$ by ${ }^{57} \mathrm{FeHBED}$ in the modified Hoagland solution. After $4 \mathrm{~d}$ without watering, plants were placed in the presence of ${ }^{57} \mathrm{FeHBED}-$ modified Hoagland solution for $24 \mathrm{~h}$ precisely, at 52 and 
54 DAS, during the vegetative phase. After labeling, the pots containing substrate and roots were rinsed four times with ultrapure water and once with non-labeled solution to remove ${ }^{57} \mathrm{Fe}$. Then, unlabeled modified Hoagland solution was used for the rest of the culture cycle until harvest.

\section{Determination of ${ }^{57} \mathrm{Fe} /{ }^{56} \mathrm{Fe}$ ratios and remobilization indices}

An aliquot of $50 \mathrm{mg}$ of dried and crushed sample was digested in a mixture of nitric acid and hydrogen peroxide (ultra-pure reagent grade) on a heated DigiPrep block (SCP Science, Canada) at $90^{\circ} \mathrm{C}$ for $3 \mathrm{~h}$ and then diluted to $50 \mathrm{ml}$ with ultrapure water. Blank samples were prepared in the same conditions. The measurement of the isotopes ${ }^{56} \mathrm{Fe}$ and ${ }^{57} \mathrm{Fe}$ contained in these solutions was performed using inductively coupled plasma mass spectrometry (ICP-MS; Perkin Elmer Nexion, USA). Helium gas was introduced into the dynamic collision cell to prevent specific polyatomic interference caused by argon and calcium oxides. Quality control solutions were prepared from a standard solution containing $100 \mathrm{mg}$ $\mathrm{ml}^{-1}$ of natural sourced Fe (Inorganic Ventures) and were used during the whole analytical sequence. The ${ }^{57} \mathrm{Fe}$ abundance $(\mathrm{A} \%)$ was calculated as atom percent and defined as $\mathrm{A} \%=100 \times{ }^{57} \mathrm{Fe}$ content $/\left({ }^{57} \mathrm{Fe}\right.$ content $+{ }^{56} \mathrm{Fe}$ content). The ${ }^{57} \mathrm{Fe}$ abundance of unlabeled plant controls ( $\mathrm{A} \%$ control) was 0.0241. The ${ }^{57} \mathrm{Fe}$ enrichment (E\%) of samples was defined as (A\% sample$\mathrm{A} \%$ control). The ${ }^{57} \mathrm{FeRSA}$ sample (relative ${ }^{57} \mathrm{Fe}$-specific allocation of the sample) was calculated as $(\mathrm{A} \%$ sample $-\mathrm{A} \%$ control $) /(\mathrm{A} \%$ labeling solution $-\mathrm{A} \%$ control $)$. The ${ }^{57} \mathrm{FeRSA}$ seeds ${ }^{57} \mathrm{FeRSA}$ (seeds+stems+leaves) ratio was calculated as (E\%

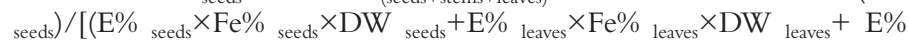
$\left.{ }_{\text {stems }} \times \mathrm{Fe} \%{ }_{\text {stems }} \times \mathrm{DW}{ }_{\text {stems }}\right) /\left(\mathrm{Fe} \%{ }_{\text {seeds }} \times \mathrm{DW}\right.$ seeds $+\mathrm{Fe} \%$ leaves $\times \mathrm{DW}$ leaves $+\mathrm{Fe} \%$ stems $\times \mathrm{DW}{ }_{\text {stems }}$ )] where $\mathrm{E} \%$ is the ${ }^{57} \mathrm{Fe}$ enrichment, $\mathrm{Fe} \%$ is the concentration of Fe as a percentage, and DW is the dry weight (Gallais et al., 2006; Masclaux-Daubresse and Chardon, 2011).

\section{Statistical analysis}

Experiments were carried out in 3-8 independent biological replicates. Data were analyzed with Kruskal-Wallis and Mann-Whitney non-parametric tests for multiple comparisons and pair comparisons, respectively. For multiple comparisons, a Tukey post-hoc test was performed when significant differences were detected $(P<0.05)$. Different letters indicate significant differences between samples. All tests were performed using the $\mathrm{R}$ software package.

\section{Results}

\section{Autophagy-deficient plants retain higher concentrations of zinc, manganese, and iron in vegetative organs}

To investigate the involvement of autophagy in micronutrient remobilization from vegetative organs to seeds during senescence, we first compared metal concentrations in vegetative organs of wild-type and several autophagy-deficient plants after the completion of the plant's life cycle in experiment 1 (Hanaoka et al., 2002; Yoshimoto et al., 2004; Thompson et al., 2005; Xiong et al., 2005; Guiboileau et al., 2012). If remobilization of metal micronutrients to seeds is impaired in plants with compromised autophagy, their concentration in the dry remains of vegetative parts should be increased compared with the wild type. Manganese $(\mathrm{Mn}), \mathrm{Fe}$, and zinc ( $\mathrm{Zn})$ concentrations were up to 2.5 times higher in dry remains of autophagy-deficient plants compared with those of wild-type plants (Fig. 1). The highest increases in metal concentrations were consistently observed in atg 5-1 and atg $4 a$ atg $4 b-1$ mutants, which are fully defective in autophagosome formation (Yoshimoto et al., 2004; Guiboileau et al., 2012). In contrast, in dry remains of $\operatorname{atg} 9.1, \operatorname{atg} 9.2$, and ATG18 RNAi, increases in $\mathrm{Mn}, \mathrm{Fe}$, and $\mathrm{Zn}$
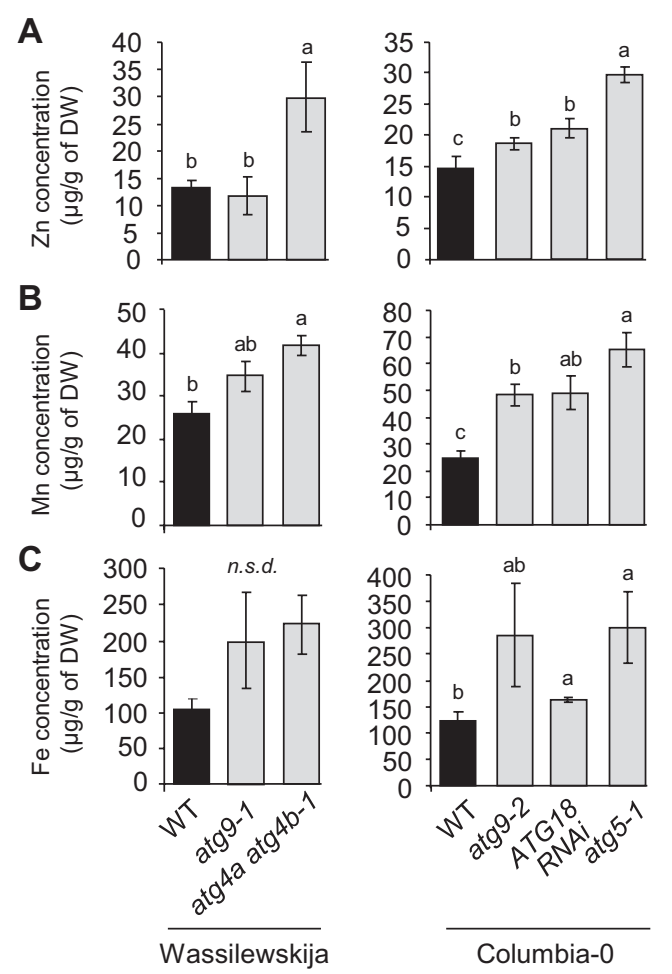

Fig. 1. Defects in autophagy lead to elevated $\mathrm{Zn}, \mathrm{Mn}$, and Fe concentrations in vegetative tissues of Arabidopsis thaliana (experiment 1). $\mathrm{Zn}(\mathrm{A}), \mathrm{Mn}(\mathrm{B})$, and $\mathrm{Fe}(\mathrm{C})$ concentrations in dry remains of vegetative tissues of wild-type plants, (Wassilewskija and Columbia-0; black bars) and autophagy-deficient plants (gray bars) in the same genetic backgrounds, grown on sand as described in Chardon et al. (2010). Results are shown as the mean \pm SE of four biological repeats. Different letters indicate significant differences between genotypes according to a Kruskal-Wallis test $(P<0.05, n=4)$ followed by a Tukey post-hoc test; $n$.s.d. indicates no significant difference.

concentrations were smaller and, in some cases, not significant. This is consistent with the observation that autophagic bodies have been detected in atg9.1, atg9.2, and ATG18 RNAi plants, indicating that autophagy is not fully compromised in these mutants (Yoshimoto et al., 2004; Guiboileau et al., 2012).

These data suggest that defects in autophagy affect micronutrient metal resorption from vegetative organs. The severity of the resorption defects appears to be related to the level of autophagy deficiency in the different genotypes tested.

\section{Distinct mechanisms lead to decrease in $\mathrm{Fe}$} concentrations in seeds of autophagy-deficient plants depending on Fe supply during the reproductive stage

To analyze further the role of autophagy in micronutrient resorption from vegetative organs to seeds, we chose to focus on the atg 5-1 mutant, which exhibited robust increases in metal concentrations in its dry remains (Fig. 1), and on Fe, a critical micronutrient that is often not sufficiently available in seeds of crop plants for human nutrition (Velu et al., 2014). Because autophagy operates a feedback loop modulating salicylic acid (SA) signaling to regulate senescence negatively, autophagydeficient plants exhibit a premature senescence phenotype which may interfere with nutrient resorption (Yoshimoto et al., 2009; Guiboileau et al., 2012). Hence, we also included in this experiment (experiment 2) the stay-green mutant sid2, 
which is defective in SA biosynthesis, and the atg5sid2 double mutant, in which autophagy is defective while senescence is delayed (Wildemuth et al., 2001; Yoshimoto et al., 2009).

Seed filling may depend on both remobilization from senescent organs and de novo uptake by roots during seed formation. In order to discriminate between the two pathways, plants were grown in parallel under two different conditions: some were supplied with sufficient Fe during their whole life cycle (Fe sufficient), while other were deprived of Fe from the onset of flowering (Fe deprivation).

Before investigating the contribution of autophagy to $\mathrm{Fe}$ remobilization from different organs and subsequent Fe loading in seeds during the reproductive stage, Fe concentrations were first measured in roots and rosette leaves during the vegetative growth of wild-type and atg 5-1 mutant plants (Supplementary Fig. S1, experiment 2, at JXB online). No significant difference in $\mathrm{Fe}$ concentration was observed between genotypes, indicating that Fe uptake and transfer to leaves was not affected in atg 5-1 at this stage (Supplementary Fig. S1). A $3.2 \pm 0.6$-fold increase in the level of ferritins $(n=4 ; P<0.05$ according to a MannWhitney test; Supplementary Fig. S2), which are involved in Fe storage in plastids (Briat et al., 2010), was observed at the vegetative stage in atg5-1 mutant leaves compared with those of wild-type plants. This result suggests that the Fe subcellular distribution is modified in atg $5-1$. Fe concentrations were then measured in leaves, stems including empty siliques, and seeds of $\operatorname{atg} 5-1$, atg5sid2, and sid2 mutants, and wild-type plants at the end of their life cycle. No differences in $\mathrm{Fe}$ concentration were observed between sid2 and wild-type plants, irrespective of the $\mathrm{Fe}$ nutrition regime. However, under Fe-sufficient nutrition, $\mathrm{Fe}$ concentrations in the atg5-1 mutant were significantly higher than those of the wild type in leaves (1.8-fold) and in stems (3.4fold) (Fig. 2), in agreement with the results presented in Fig. 1. The increase in Fe concentration in atg 5-1 vegetative organs was associated with a trend towards decreased seed Fe concentration (Fig. 2). Similar results were observed in experiment 3 comparing wild-type and atg 5-1 mutant plants under higher light conditions (Supplementary Fig. S3), confirming the robustness of this observation. In experiment 3 , metal concentrations were also measured in roots and rosette leaves at the beginning of seed filling (Supplementary Fig. S4). Under Fe-sufficient conditions, higher Fe concentrations were observed in rosette leaves of the atg5-1 mutant than in those of wild-type plants already at this early stage, whereas no difference was detected at the root level (Supplementary Fig. S4). These data suggest that, at least initially, $\mathrm{Fe}$ is remobilized from leaves rather than from roots. Both the increase in Fe concentration in vegetative organs and the decrease in seeds observed in atg 5-1 tended to be reversed to a large extent in atg5sid2 (Fig. 2, experiment 2), suggesting that these effects are in part due to early leaf senescence.

Under Fe deprivation, Fe concentrations were lower in leaves and seeds irrespective of the genotype, as expected (Fig. 2). In contrast to the Fe-sufficient nutrition, $\mathrm{Fe}$ concentrations in vegetative organs of the atg 5-1 mutant displayed only a moderate and non-significant increase (1.2-fold) with respect to the wild type, while Fe concentration was significantly decreased by $20 \%$ in seeds (Fig. 2). These effects were not reversed in the atg 5 sid 2 mutant, suggesting that they are due to impaired autophagy rather than early senescence.

Taken together, these data indicate that the atg 5-1 mutant is affected in Fe resorption from vegetative organs to seeds by distinct mechanisms under sufficient Fe supply or Fe deprivation during the reproductive period.

\section{Defective autophagy leads to a strong decrease in the pool of Fe allocated to seeds}

To evaluate the impact of autophagy on the redistribution of Fe pools between vegetative organs and seeds, we calculated Fe mass distribution among organs. For this purpose, we first determined the total biomass distribution as well as the harvest index, which is defined as the ratio of seed biomass

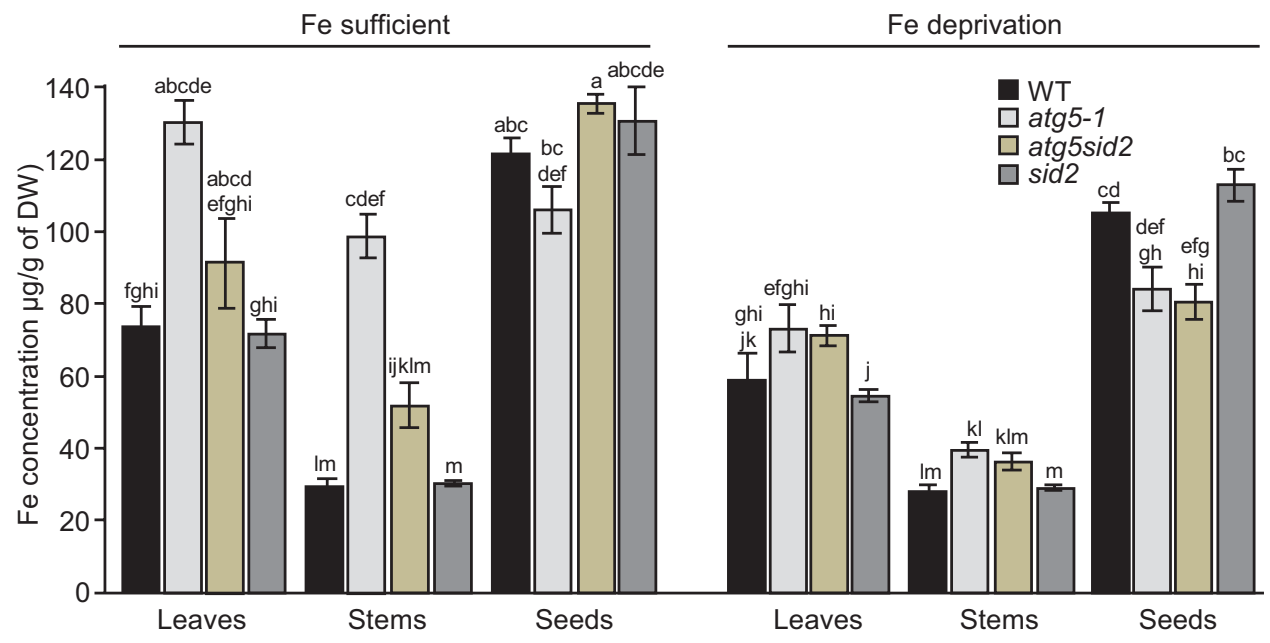

Fig. 2. Distinct mechanisms lead to a decrease in Fe concentration in seeds of autophagy-deficient plants depending on Fe supply during the reproductive stage in Arabidopsis thaliana (experiment 2). Fe concentrations in leaves, stems (including empty siliques), and seeds of wild-type (WT, black bars), atg5-1 mutant (light gray bars), atg5sid2 double mutant (intermediate gray bars), and sid2 (dark gray bars) mutant plants grown on sand/perlite (1/1) substrate watered with modified Hoagland medium. Iron was supplied (Fe sufficient) or not (Fe deprivation) during the reproductive stage. Results are shown as the mean \pm SE of five biological repeats. Different letters indicate significant differences according to a Kruskal-Wallis test $(P<0.05, n=5)$ followed by a Tukey post-hoc test. (This figure is available in color at JXB online.) 
relative to the whole aerial biomass of the plant after completion of the life cycle. As previously reported (Guiboileau et al., 2012), loss of $A T G 5$ function led to a strong reduction of total dry biomass (2.8-fold; Supplementary Fig. S5) and an even more severe defect in seed production causing a decrease in the harvest index (Supplementary Fig. S6). These effects were not significantly reversed in the atg 5 sid 2 mutant, and were also observed when plants were deprived of Fe during the reproductive phase (Supplementary Figs S5, S6).

Taking biomass and Fe concentrations into account, Fe content $\left[\mathrm{Fe}_{\text {content }}(\mu \mathrm{g})=\mathrm{Fe}_{\text {concentration }}\left(\mu \mathrm{g} \mathrm{mg}^{-1}\right.\right.$ of $\left.\mathrm{DW}\right) \times \mathrm{Organ}_{\text {biomass }}$ (mg DW)] was determined for each organ (Fig. 3A). First, we observed a lower $\mathrm{Fe}$ content under $\mathrm{Fe}$ deprivation in all genotypes, indicating that de novo Fe uptake during seed formation contributes to the total $\mathrm{Fe}$ content independently of autophagy (Fig. 3A). Although the atg5-1 mutant displayed significantly higher Fe concentrations than the wild type in vegetative organs (Fig. 2), its total Fe content was strongly decreased compared with the wild type due to its much lower biomass (Fig. 3A; Supplementary Fig. S5). Disrupting the sid2 gene did not restore Fe accumulation in atg 5-1, indicating that this defect is not due to the premature senescence of the atg 5-1 mutant.

Compared with that of the wild type, lower Fe contents were observed in vegetative organs of atg 5-1 (-35\%) and atg5 sid2 (-24\%) mutants specifically under Fe deprivation but not under Fe-sufficient nutrition (Fig. 3A). This result indicates that Fe supply during the reproductive stage provides vegetative organs of autophagy-deficient plants with Fe even though they undergo premature leaf senescence. This suggests that $\mathrm{Fe}$ is accumulated in vegetative tissues during the early steps of the reproductive stage.
The Fe content of seeds from plants growing under Fe deprivation was dramatically decreased by $-80 \%$ and $-70 \%$ in atg $5-1$ and $\operatorname{atg} 5$ sid 2 mutants compared with the wild type, respectively (Fig. 3A). Fe content is therefore much more severely affected by the lack of autophagy in seeds than in other organs due to a cumulative effect of decreased seed production and decreased seed Fe concentration. Fe supply during the reproductive stage partially restored the Fe content of atg 5 sid 2 seeds but had no effect on the Fe content of atg5-1 seeds. This result indicates that de novo $\mathrm{Fe}$ uptake during seed formation can provide seeds with $\mathrm{Fe}$ in autophagy-deficient plants, but only when premature senescence is prevented. This suggests that such a contribution takes place during the late steps of the reproductive stage, when atg 5-1 but not atg 5 sid 2 displays leaf senescence symptoms.

\section{Impaired autophagy affects translocation of Fe remobilized from vegetative organs to seeds}

We then analyzed the impact of the absence of autophagy on the efficiency of total Fe translocation to seeds (Fe content seeds Fe content (leaveststemstseeds), under Fe-sufficient nutrition and Fe deprivation (Fig. 3B). The efficiency of total Fe translocation to seeds was indistinguishable between wild-type and sid2 mutant plants, representing $50-55 \%$ of the total Fe content of the plant, irrespective of the Fe nutrition regime. In contrast, the efficiency of total Fe translocation was strongly decreased in atg 5-1 and atg 5 sid 2 mutants. Under Fe-sufficient nutrition, Fe translocation efficiency was decreased by $63 \%$ in the atg 5 1 mutant and by only $35 \%$ in the atg 5 sid 2 mutant, confirming that both autophagy and premature senescence limit Fe
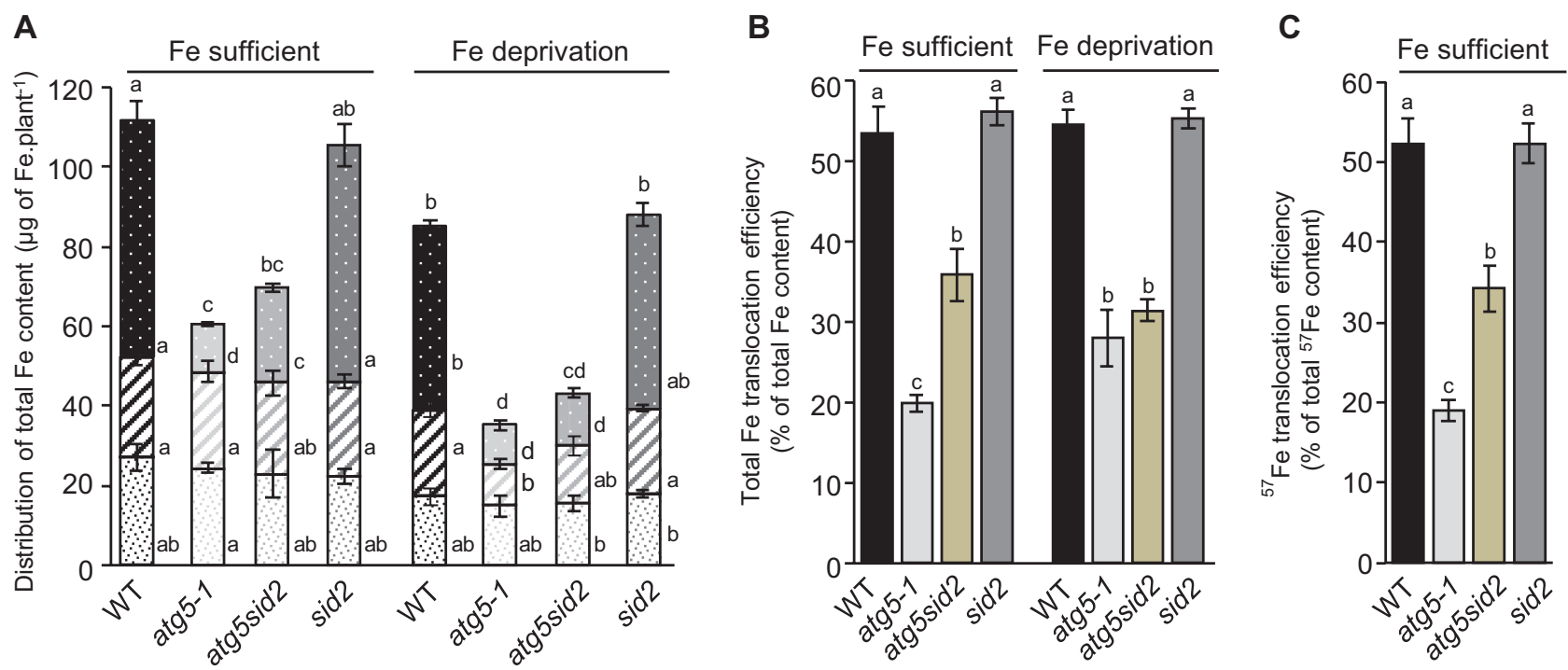

Fig. 3. Distribution of total Fe content and Fe translocation to seeds are dramatically affected in atg5-1 and atg5sid2 mutants of Arabidopsis thaliana (experiment 2). (A) Distribution of Fe between leaves (filled columns), stems including empty siliques (diagonal stripes), and seeds (white dots) of plants are represented for the wild-type (WT, black bars), the atg5-1 (light gray bars), the atg5sid2 (intermediate gray bars), and the sid2 (dark gray bars) mutant plants. (B) Total Fe translocation efficiency calculated as the ratio between the Fe content in seeds and the Fe content in the whole plant (Fe seed/(Fe

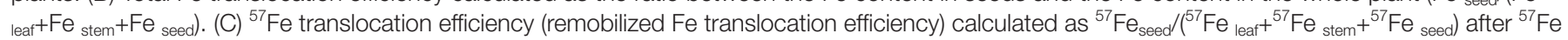
pulse labeling at the vegetative stage. Plants were grown on sand/perlite (1/1) substrate watered with modified Hoagland medium. Fe was supplied (Fe sufficient) or not (Fe deprivation) during the reproductive stage. Results are shown as the mean $\pm \mathrm{SE}$ of five biological repeats. Different letters indicate significant differences between genotypes and conditions according to a Kruskal-Wallis test $(P<0.05, n=5)$ followed by a Tukey post-hoc test. (This figure is available in color at JXB online.) 
translocation to seeds under these conditions. Under Fe deprivation, total $\mathrm{Fe}$ translocation efficiency was decreased to a similar extent (42-48\%) in atg 5-1 and atg5sid2 mutants, indicating that premature senescence has no impact on total Fe translocation when $\mathrm{Fe}$ is not provided during the reproductive phase.

In experiment 3 performed under higher light conditions, similar total $\mathrm{Fe}$ translocation efficiencies of $50-55 \%$ were measured in the wild type (Supplementary Fig. S7). However, in the atg 5-1 mutant, the total Fe translocation efficiency was further decreased under Fe deprivation. We hypothesize that light stress may have modified the timing of leaf senescence or amplified the effect of Fe deficiency.

Using Fe deprivation to estimate the relative contribution of root uptake and remobilization from leaves may be biased by the activation of compensatory mechanisms under Fe deficiency (Pottier et al., 2014). Then, to monitor fluxes specifically between senescing organs and seeds independently of uptake from soil, we performed a ${ }^{57} \mathrm{Fe}$ labeling pulse-chase experiment. A pulse of ${ }^{57} \mathrm{Fe}$ was provided in the nutritive medium of young rosette plants. Pots and substrate were then thoroughly washed to avoid further ${ }^{57} \mathrm{Fe}$ uptake during the chase period. Plants were subsequently watered with nutritive solution containing non-labeled Fe until the end of the life cycle (Fe-sufficient nutrition). At the end of the life cycle, the relative abundance of ${ }^{57} \mathrm{Fe}$ was determined in each organ by ICP-MS. From these data, we first calculated ${ }^{57} \mathrm{FeRSA}$ values which reflect the dilution of ${ }^{57} \mathrm{Fe}$ in leaves, stems, and seeds for each genotype (Supplementay Table S1). Leaves displayed the highest ${ }^{57} \mathrm{FeRSA}$ values (Supplementary Table S1), which is consistent with the fact that pulse labeling was performed at the rosette stage when other organs were not yet present. Conversely, stems showed consistently the lowest ${ }^{57} \mathrm{FeRSA}$, suggesting that both $\mathrm{Fe}$ remobilization from rosette leaves and de novo $\mathrm{Fe}$ uptake from soil contributed to stem total $\mathrm{Fe}$ (Supplementary Table S1). Finally seeds displayed an intermediate ${ }^{57} \mathrm{FeRSA}$ level which could reflect a mixed contribution of remobilization from leaves and stems, and possibly de novo Fe uptake during the reproductive stage. The lower ${ }^{57} \mathrm{FeRSA}$ in sid 2 and atg 5 sid 2 seeds may be due to delayed senescence allowing prolonged uptake of ${ }^{56} \mathrm{Fe}$ and further dilution of the label. To obtain further information on the contribution of these different sources of $\mathrm{Fe}$ to seed $\mathrm{Fe}$, we calculated the ${ }^{57} \mathrm{FeRSA}{ }_{\text {seeds }}{ }^{57} \mathrm{FeRSA}$ (seeds+stemstleaves) ratio (Table 1), which compares ${ }^{57} \mathrm{Fe}$ dilution between the seeds and the whole

Table 1. ${ }^{57} \mathrm{Fe} R S A_{\text {seeds }}{ }^{57} \mathrm{Fe} R S A_{\text {(seeds+stems+leaves) }}$ ratios in wild-type Columbia-0, atg5-1, atg5sid2, and sid2 mutant plants which have undergone ${ }^{57} \mathrm{Fe}$ pulse labeling at the vegetative stage

\begin{tabular}{ll}
\hline Genotype & ${ }^{\mathbf{5 7}} \mathbf{F e R S A} \boldsymbol{A}_{\text {seeds }}{ }^{{ }^{57}}{ }^{\text {FeRSA }}$ (seeds+stems+leaves) \\
\hline Col-0 & $0.96 \pm 0.02$ \\
atg5-1 & $0.98 \pm 0.07$ \\
atg5sid2 & $0.92 \pm 0.04$ \\
sid2 & $0.88 \pm 0.04$ \\
\hline
\end{tabular}

No significant differences in ${ }^{57} \mathrm{FeRSA}$ seeds $/{ }^{57} \mathrm{FeRSA}$ (seeds + stems + leaves) ratios were observed between genotypes according to Kruskal-Wallis test $(P<0.05, n=5)$. aerial part of the plant (Gallais et al., 2006). A ${ }^{57} \mathrm{FeRSA}$ seeds $/{ }^{57}$ $\mathrm{FeRSA}_{\text {(seeds+stems+leaves) }}$ ratio lower than 1 indicates that the ${ }^{56} \mathrm{Fe}$ absorbed de novo during the reproductive stage contributes mainly to seed Fe content, while a ratio higher than 1 indicates that the ${ }^{56} \mathrm{Fe}$ absorbed during the reproductive stage contributes mainly to the Fe content of vegetative tissues. Here, ${ }^{57} \mathrm{FeRSA}$ seeds $/$ ${ }^{57} \mathrm{FeRSA}_{\text {(seeds+stems+leaves) }}$ ratios were almost equal to 1 , indicating that ${ }^{57} \mathrm{Fe}$ dilution is similar in seeds and in the whole plant, and no significant differences were observed between genotypes (Table 1). Such a result shows that ${ }^{56} \mathrm{Fe}$ taken up during the reproductive stage contributes to a similar extent to Fe content of seeds and to that of the leaves and stems. Two scenarios may account for this value, either (i) direct ${ }^{56} \mathrm{Fe}$ fluxes to the vegetative organs and to the seeds are perfectly balanced and lead to similar dilutions or (ii) ${ }^{56} \mathrm{Fe}$ is first loaded in vegetative organs, which subsequently provide $\mathrm{Fe}$ with a pre-determined RSA to the seeds. Finally, combining the ${ }^{57} \mathrm{Fe} /{ }^{56} \mathrm{Fe}$ ratio with Fe concentration and DW, we calculated the ${ }^{57} \mathrm{Fe}$ content seed $_{\text {s }}$ / ${ }^{57} \mathrm{Fe}$ content (leaves+stems+seeds) $_{\text {ratio (i.e. the proportion of }{ }^{57} \mathrm{Fe}}$ translocated from the rosettes and the stems to the seeds). Compared with the apparent $\mathrm{Fe}$ translocation ratio, this ratio takes into account Fe taken up only during the vegetative stage and is thus a good indicator of the Fe remobilization efficiency from vegetative organs to seeds even when $\mathrm{Fe}$ is supplied during the reproductive stage (Fig. 3C).Values of the ${ }^{57} \mathrm{Fe}$ content ${ }_{\text {seed }} /$ ${ }^{57} \mathrm{Fe}$ content (leaves + stems+seeds) $_{\text {ratio }}$ rate very similar to those of the $\mathrm{Fe}$ content $_{\text {seed }} / \mathrm{Fe}$ content (leaveststemstseeds) $_{\text {) }}$ ratio (Fig. 3B) irrespective of the genotype. This result suggests that, under our experimental conditions, the loading of $\mathrm{Fe}$ to the seeds is mostly achieved by $\mathrm{Fe}$ remobilization from the vegetative organs according to scenario (ii), even though Fe is still taken up from the soil during the reproductive stage (Fig. 3A). Thus, the intermediate ${ }^{57} \mathrm{FeRSA}$ level measured in seeds is only due to the mixed contribution of remobilization from vegetative organs (Supplementary Table S1) rather than to dilution by ${ }^{56} \mathrm{Fe}$ originating directly from root uptake. This is in apparent contradiction to a value of ${ }^{57} \mathrm{FeRSA}$ seeds $/{ }^{57} \mathrm{FeRSA}$ (seeds+stemstleaves) of 1 , indicating that de novo uptake during the reproductive growth contributes similarly to Fe content of vegetative organs and seeds (Table 1). This apparent discrepancy may be solved if we consider scenario (ii) which suggests an indirect involvement of the de novo Fe uptake to seed Fe content though a two-step mechanism, as described in the Discussion.

\section{The lack of autophagy also impacts $Z n$ and $M n$ translocation to seeds}

Before investigating the putative involvement of autophagy in the translocation of $\mathrm{Zn}$ and $\mathrm{Mn}$ to seeds, their concentrations were measured in roots and young rosette leaves during the vegetative stage, to test whether atg 5-1 affects $\mathrm{Mn}$ or $\mathrm{Zn}$ uptake and transfer to leaves at this stage (Supplementary Fig. S1). For $\mathrm{Zn}$, no significant differences were observed in leaves and roots, as was the case for $\mathrm{Fe}$, indicating similar $\mathrm{Zn}$ uptake in both genotypes (Supplementary Fig. S1). In experiment 3, metal concentrations were also measured in roots and rosette 
leaves at the beginning of seed filling (Supplementary Fig. S4). At this developmental stage, the $\mathrm{Zn}$ concentration was significantly higher in both roots and leaves of the atg 5-1 mutant than in those of wild-type plants (Supplementary Fig. S4). Such a result suggests therefore that unlike Fe, autophagy-dependent $\mathrm{Zn}$ remobilization during seed loading originates from both roots and leaves. The $\mathrm{Mn}$ concentration in roots was more than twice as high in the atg 5-1 mutant compared with wild-type plants at the vegetative stage (Supplementary Fig. S1, experiment 2). In experiment 3, root Mn concentration measured at the beginning of seed loading was also much higher in atg 5-1 (Supplementary Fig. S4). These observations indicate that disruption of the ATG5 gene strongly perturbs Mn uptake and/ or $\mathrm{Mn}$ remobilization from roots during both vegetative and reproductive growth.

Concentrations were studied at the end of the plant life cycle in order to determine $\mathrm{Mn}$ and $\mathrm{Zn}$ translocation efficiencies under Fe-sufficient nutrition, following the same approach as for Fe. In wild-type plants, $\mathrm{Zn}$ and $\mathrm{Mn}$ translocation efficiencies were $38 \%$ and $24 \%$, respectively (Fig. 4). In atg 5-1 mutants, total translocation efficiencies of these elements were both strongly affected with respect to the wild type. Similar results were observed in experiment 3 performed under higher light conditions (Supplementary Fig. S7). Also, no significant differences were observed between atg 5-1 and atg5sid 2 mutant plants (Fig. 4). Thus, a defect in autophagy affects not only Fe translocation but also, to various extents, translocation of other micronutrients, even in the absence of premature senescence. In view of the results obtained at earlier stages (Supplementary Figs S1, S4), remobilization from roots should be taken into account to evaluate fully the importance of autophagy for $\mathrm{Zn}$ and especially for $\mathrm{Mn}$ translocation to seeds. The ratios calculated on the basis of leaf and stem Mn and Zn content (Fig. 4) probably underestimate the effect of impairing autophagy.
A

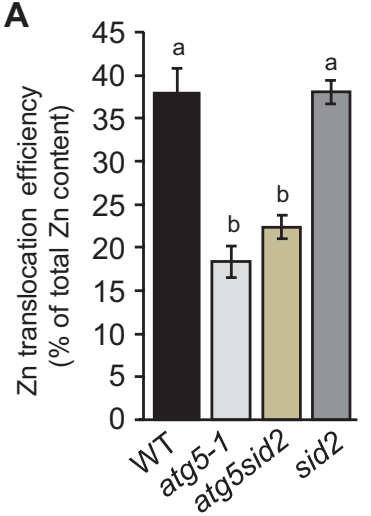

B

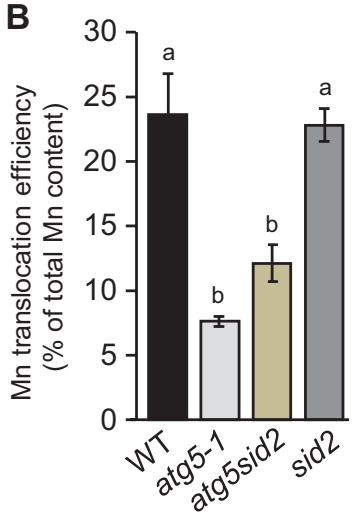

Fig. 4. Translocation efficiencies of $\mathrm{Zn}(\mathrm{A})$ and $\mathrm{Mn}(\mathrm{B})$ are also affected in atg5-1 and atg5sid2 mutant plants of Arabidopsis thaliana (experiment 2). Translocation efficiencies were calculated for wild-type (WT), atg5-1, atg5sid2, and sid2 mutant plants, as the ratio between the micronutrient content in seeds and the micronutrient content in the whole plant. Plants were grown on sand/perlite (1/1) substrate watered with modified Hoagland medium containing Fe during the whole plant cycle. Results are shown as the mean \pm SE of five biological replicates. Different letters indicate significant differences between genotypes according to a KruskalWallis test $(P<0.05, n=5)$ followed by a Tukey post-hoc test. (This figure is available in color at $J X B$ online.)

\section{Discussion}

Because of its poor solubility in most soils, its essential roles in plant cellular processes, and due to its insufficiency in the human diet, many investigations have been undertaken during the last decades to decipher the route of Fe within the plant from its uptake from the rhizosphere to its loading into seeds. Both uptake from soil and remobilization from senescent organs participate in grain loading and thereby contribute to Fe use efficiency (Pottier et al., 2014). To date, little is known about the mechanisms involved in Fe remobilization from senescent source organs during seed formation. A first step of disassembling of organelles, proteins, and various macromolecules is required prior to nutrient reallocation. During senescence, numerous genes involved in catabolism and degradation mechanisms including genes involved in autophagy are up-regulated following a well-established schedule (Breeze et al., 2011). Thus, autophagy may be a limiting step in making nutrients available for further reallocation towards new organs. In the present work, we have investigated the involvement of autophagy in metal micronutrient remobilization from vegetative organs to seeds. Analyzing a range of autophagy mutants, we found that the defect in nutrient remobilization correlated with the severity of the defect in autophagosome formation (Fig. 1). Accordingly, the severe defect in autophagy in the atg5-1 mutant leads to a decrease in seed Fe concentration and a drastic reduction in Fe translocation efficiency to seeds (Figs 2, 3; Supplementary Fig. S3). Interestingly, this defect could be alleviated by providing Fe to the roots only when atg 5-1 premature senescence was prevented (Fig. 3A). These results, together with the outcome of the ${ }^{57} \mathrm{Fe}$ pulse labeling experiment, suggest that the ${ }^{56} \mathrm{Fe}$ taken up by the roots during seed formation contributes indirectly to seed $\mathrm{Fe}$ content (Table 1; Fig. 3B, C). Finally, we found that autophagy plays roles not only in Fe but also in $\mathrm{Zn}$ and $\mathrm{Mn}$ translocation to seeds, supporting the importance of this mechanism for optimal loading of mineral nutrients to seeds (Fig. 4).

\section{Mineral translocation efficiency to seeds is constant in Arabidopsis}

Total iron translocation efficiency of $A$. thaliana Columbia-0 wild-type was within the $50-55 \%$ range irrespective of light conditions or $\mathrm{Fe}$ nutrition regime (Fig. 3B; Supplemental Fig. S5). Fe uptake observed during the reproductive stage under Fe-sufficient nutrition therefore has no impact on Fe translocation efficiency of wild-type plants (Fig. 3A, B). A previous study also found that half of the Fe content of Arabidopsis leaves was remobilized during senescence (Himelblau and Amasino, 2001), even though the ecotype, the photoperiod, and the growth conditions were different. Thus, Fe translocation efficiency appears to be remarkably stable in $A$. thaliana. The other micronutrients studied in this work exhibited lower total translocation efficiencies than $\mathrm{Fe}$ (Fig. 4; Supplementary Fig. S7). We found, however, that Zn is better translocated than $\mathrm{Mn}$, which is also in agreement with results obtained by Himelblau and Amasino (2001). In contrast, Maillard et al. (2015) found large variation in leaf 
mineral nutrient resorption between different species. Pottier et al. (2015a) also found variation in metal resorption from leaves from different poplar genotypes. However, remobilization from leaves rather than translocation to seeds was analyzed in these studies.

\section{Seed iron first transits through vegetative organs}

The Fe that is taken up de novo during the reproductive stage may be loaded first in young parts of the vegetative organs or directly into seeds. The atg5-1 mutant, which undergoes premature senescence, displayed a similar increase of total $\mathrm{Fe}$ content to that in the other genotypes when $\mathrm{Fe}$ is provided during the reproductive stage (Fig. 3A). This observation indicates that Fe uptake after the onset of flowering occurs essentially during the early period of the reproductive stage, prior to the senescence of atg5-1 mutant leaves. Moreover, the atg 5-1 mutant accumulated de novo absorbed Fe preferentially in vegetative organs while it was translocated more efficiently to seeds when premature senescence was prevented (Fig. 3A). If senescence, which eventually leads to cell death, takes place too early, the lapse of time during which nutrients can be translocated between leaves and seeds is shortened, resulting in decreased nutrient translocation efficiency. These results suggest a two-stage process in which Fe taken up by roots is transiently accumulated in vegetative organs prior to its remobilization to the seeds, as illustrated in Fig. 5. This hypothesis also accounts for the similar values observed for total $\mathrm{Fe}$ and ${ }^{57} \mathrm{Fe}$ remobilization efficiencies as well as for the similar ${ }^{57} \mathrm{Fe}$ dilution in seeds and vegetative organs (leaves and stems) reflected in the ${ }^{57} \mathrm{FeRSA}_{\text {seeds }}$ / ${ }^{57}$ FeRSA (seeds+stems+leaves) ratio almost equal to 1 observed in all genotypes after pulse labeling during the vegetative phase (Fig. 3B, C; Table 1). Waters and Grusak (2008) concluded that de novo uptake is at least as important as remobilization for seed filling. However, they were using different conditions and did not consider the possibility that minerals have to transit to vegetative organs before being translocated to seeds.

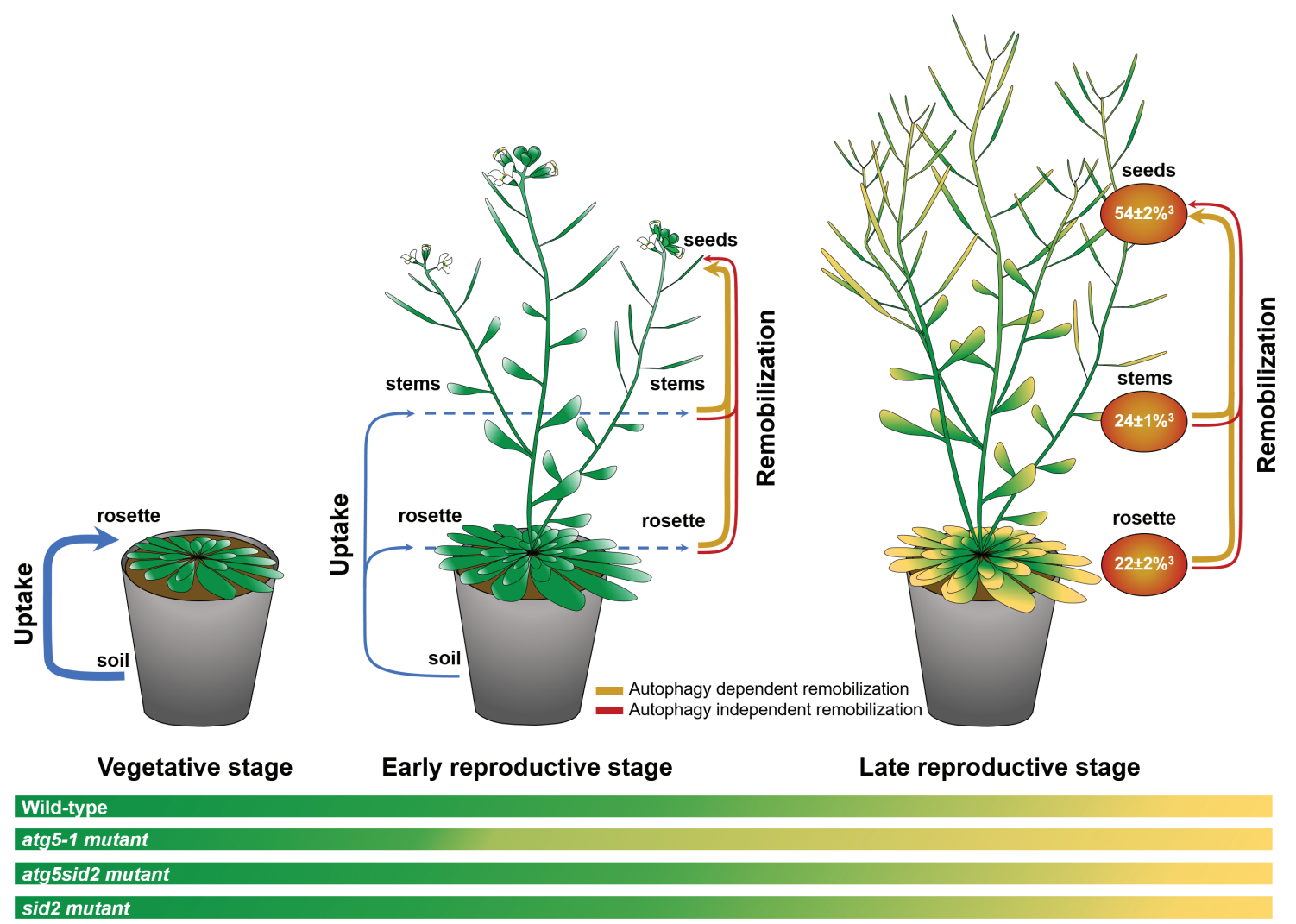

Fig. 5. Iron fluxes in wild-type Arabidopsis thaliana growing under Fe-sufficient conditions, in vegetative, early reproductive, and late reproductive stages, based on results obtained in wild-type and autophagy-deficient plants. Thicknesses of the uptake and remobilization arrows are proportional to fluxes. Fe distribution (brown circles) is expressed as a percentage of total Fe of wild-type plants harvested after completion of the life cycle. Early reproductive stage is defined as the period of premature senescence in the atg5-1 mutant. Late reproductive stage is defined as the period of senescence in the wild type, when the atg5-1 mutant is already dry. Together, the results obtained indicate that (i) most of the Fe uptake $\left(71 \pm 4 \%{ }^{1}\right)$ takes place during the vegetative growth; (ii) Fe uptake after the onset of flowering $\left(29 \pm 5 \%^{2}\right)$ occurs mostly during the early reproductive stage; (iii) Fe loading into seeds $\left(54 \pm 2 \%^{3}\right)$ is mainly achieved through remobilization rather than a direct contribution from Fe root uptake; and (iv) in the wild type, $35 \pm 2 \%{ }^{4}$ of the total Fe content is loaded to seeds through autophagy-dependent remobilization, and $19 \pm 2 \%{ }^{5}$ is loaded through autophagy independent remobilization. ${ }^{1}$ Total Fe content of plants growing in Fe deprivation conditions as a percentage of total iron of plants growing in Fe-sufficient conditions. ${ }^{2}$ Difference between the total Fe content of plants growing in Fe-sufficient conditions and the total Fe content of plants growing in Fe deprivation conditions as a percentage of total Fe of plants growing in Fe-sufficient conditions. ${ }^{3} \mathrm{Fe}$ content in seeds, stems, and rosette leaves of wild-type plants as percentages of total Fe of wild-type plants growing in Fe-sufficient conditions. ${ }^{4}$ Difference between the percentage of Fe loaded in seeds of wild-type plants and the percentage of Fe loaded in seeds of atg5sid2 mutant plants. ${ }^{5}$ Difference between the percentage of Fe content in seeds and the percentage of Fe loaded in seeds through autophagy-dependent remobilization. 


\section{A possible contribution of root metal micronutrient stores to seed filling}

Our work has not addressed the contribution of root Fe stores to total plant $\mathrm{Fe}$ and its fate during senescence. The experimental set up that was chosen, growth in a sand-perlite mixture, precluded harvesting the whole root system at the end of the plant's life cycle. Moreover, rigorous analysis of root micronutrient content requires the removal through desorption of cations that are adsorbed on the root but not taken up by living cells. However, at the end of the life cycle, the roots are dead, cellular ion content is released, and desorption becomes meaningless. Growing plants under hydroponic conditions would allow collection and desorption of the entire root biomass. However, this cultivation system affects nutrient distribution between roots and shoots, and is not suitable for seed production (Diaz et al., 2008).

Nevertheless, we collected roots at earlier stages of plant development. Root $\mathrm{Fe}$ concentrations were not affected in the atg 5-1 mutant at the vegetative stage or at the onset of silique development (Supplementary Figs S1, S4). This suggests that the defects in Fe distribution observed in the aerial parts of atg 5-1 are not related to root function. Roots are the site of de novo $\mathrm{Fe}$ uptake as well as a vegetative organ in which Fe may be stored for subsequent remobilization. The results obtained using ${ }^{57} \mathrm{Fe}$ labeling argue in favor of a model in which the $\mathrm{Fe}$ taken up by roots during the reproductive phase first transits through vegetative organs. However, these results do not exclude a contribution of the Fe stored in roots to seed filling as well as an impact of autophagy defects on remobilization of root $\mathrm{Fe}$ pools at later stages. In contrast, differences in $\mathrm{Zn}$ concentrations in both rosette leaves and roots at the onset of seed filling suggest that root $\mathrm{Zn}$ pools may be reallocated together with leaf $\mathrm{Zn}$ pools at the reproductive stage (Supplementary Fig. S4). In addition, differences in Mn concentrations were observed in roots at the vegetative stage and at the early reproductive stage, indicating that autophagy influences its uptake or distribution (Supplementary Figs S1, S4). The importance of root $\mathrm{Mn}$ pools for Mn redistribution has already been documented in Brassica napus subjected to Mn deficiency (Maillard et al., 2015). Regarding nitrogen, remobilization from roots to flowering stems and reproductive organs was shown to make a minor contribution in $A$. thaliana (Diaz et al., 2008). In B. napus, such remobilization contributes only to $11.1 \%$ of the pod nitrogen content (Rossato et al., 2001). Regarding Zn, no decrease of its root content was observed between anthesis and maturity in rice (Jiang et al., 2008 ), while, in wheat, it was decreased by $50 \%$, indicating that remobilization of $\mathrm{Zn}$ from roots varies according to species (Kutman et al., 2012). In A. thaliana, to our knowledge, no evidence for micronutrient remobilization from roots has been reported. Also, root senescence related to seed loading still has to be investigated (Hammond and White, 2008; Lynch and Brown, 2008). Even though roots were shown to contain higher $\mathrm{Fe}$ concentrations than shoots in $A$. thaliana (Cassin et al., 2009; Reyt et al., 2015; Pottier et al., 2015b; Eroglu et al., 2016; Li et al., 2016; this study), their contribution to seed filling remains to be demonstrated.

\section{Harnessing autophagy to improve seed nutrient content}

We found that autophagy is a crucial component of micronutrient filling to seeds and thus a strong determinant of seed quality. Although autophagy was shown to be induced during senescence (van der Graaff et al., 2006; Breeze et al., 2011; Htwe et al., 2011), significant amounts of nutrients present in vegetative organs, $30 \%$ of $\mathrm{N}$ in optimal conditions, $46 \%$ of $\mathrm{Fe}$, and even larger proportions of other micronutrients, are not reallocated to seeds (Fig. 4; Guiboileau et al., 2012). Thus, increasing the autophagy process further specifically during seed filling may be a powerful approach to increase the pool of nutrients available for subsequent translocation to seeds. However, it will also be necessary to increase seed storage capacity. In seeds, Fe is highly concentrated in vacuoles of the aleurone layer in cereals (Moore et al., 2012) and of the proto-endodermis in several dicot species (Mary et al., 2015; Ibeas et al., 2017). These locations probably minimize the damage that could be caused by excess free Fe. Additional parallel research on the mechanisms of Fe storage in seeds is also needed. Moreover, autophagy is a complex mechanism subjected to a subtle multiscale regulation (Yoshimoto, 2012; Masclaux-Daubresse et al., 2017). Further investigations on the regulation of autophagy may thus help improve grain yield by bioengineering strategies or marker-assisted breeding.

\section{Supplementary data}

Supplementary data are available at JXB online.

Fig. S1. Fe, Mn, and Zn concentrations in roots and rosette leaves measured during vegetative growth in Col-0 wild type and the atg 5-1 mutant (experiment 2).

Fig. S2. Ferritins are more abundant in vegetative tissues of the atg 5-1 mutant than in those of Col-0 wild type (experiment 1).

Fig. S3. The increase in Fe concentration in leaves and stems of the atg 5-1 mutant is associated with a significant decrease in seed Fe concentration (experiment 3).

Fig. S4. Fe, Mn, and $\mathrm{Zn}$ concentrations in roots and rosette leaves measured at the onset of seed loading in Col-0 wild type and the atg 5-1 mutant (experiment 3).

Fig. S5. Total dry biomass and dry biomass distribution between organs are dramatically affected in atg 5-1 and atg 5 sid2 mutants, even under Fe-sufficient conditions (experiment 2).

Fig. S6. Harvest index is affected in autophagy-deficient plants even in the absence of premature leaf senescence, independently of the Fe supply conditions (experiment 2).

Fig. S7. Total seed production and total iron translocation efficiency are dramatically affected in the atg 5-1 mutant even under Fe-sufficient conditions (experiment 3).

Fig. S8. Translocation efficiencies of $\mathrm{Zn}(\mathrm{A})$ and $\mathrm{Mn}(\mathrm{B})$ are affected in the atg 5-1 mutant (experiment 3 ).

Table S1. Relative ${ }^{57} \mathrm{Fe}$-specific allocation $\left({ }^{57} \mathrm{FeRSA}\right)$ in leaves, stems including empty siliques, and seeds in wild-type Co-0, $\operatorname{atg} 5-1$, atg $5 \operatorname{sid} 2$, and sid 2 mutant plants which have undergone a ${ }^{57} \mathrm{Fe}$ pulse labeling at the vegetative stage (experiment 2). 


\section{Acknowledgements}

The authors are grateful to Cindy Victor and Sara Martins for their contribution to harvests, and Adrien Tallois and Yann Kourouma for help with elemental analysis. This work was supported by the Centre National de la Recherche Scientifique and the Agence Nationale pour la Recherche grants (ANR-11-BSV6-000 and ANR-16-CE20-0019-02) to ST and by the Région Ile-de-France through a grant from the DIM Astréa to MP. The I2BC and IJPB benefit from the support of the LabEx Saclay Plant Sciences-SPS (ANR-10-LABX-0040-SPS).

\section{References}

Breeze E, Harrison E, McHattie S, et al. 2011. High-resolution temporal profiling of transcripts during Arabidopsis leaf senescence reveals a distinct chronology of processes and regulation. The Plant Cell 23, 873-894.

Briat JF, Duc C, Ravet K, Gaymard F. 2010. Ferritins and iron storage in plants. Biochimica et Biophysica Acta 1800, 806-814.

Cassin G, Mari S, Curie C, Briat JF, Czernic P. 2009. Increased sensitivity to iron deficiency in Arabidopsis thaliana overaccumulating nicotianamine. Journal of Experimental Botany 60, 1249-1259.

Chardon F, Barthélémy J, Daniel-Vedele F, Masclaux-Daubresse C. 2010. Natural variation of nitrate uptake and nitrogen use efficiency in Arabidopsis thaliana cultivated with limiting and ample nitrogen supply. Journal of Experimental Botany 61, 2293-2302.

Chung T, Phillips AR, Vierstra RD. 2010. ATG8 lipidation and ATG8mediated autophagy in Arabidopsis require ATG12 expressed from the differentially controlled ATG12A and ATG12B loci. The Plant Journal 62, 483-493.

Diaz C, Lemaître T, Christ A, Azzopardi M, Kato Y, Sato F, MorotGaudry JF, Le Dily F, Masclaux-Daubresse C. 2008. Nitrogen recycling and remobilization are differentially controlled by leaf senescence and development stage in Arabidopsis under low nitrogen nutrition. Plant Physiology 147, 1437-1449.

Doelling JH, Walker JM, Friedman EM, Thompson AR, Vierstra RD. 2002. The APG8/12-activating enzyme APG7 is required for proper nutrient recycling and senescence in Arabidopsis thaliana. Journal of Biological Chemistry 277, 33105-33114.

Durrett TP, Gassmann W, Rogers EE. 2007. The FRD3-mediated efflux of citrate into the root vasculature is necessary for efficient iron translocation. Plant Physiology 144, 197-205.

Eroglu S, Meier B, von Wirén N, Peiter E. 2016. The vacuolar manganese transporter MTP8 determines tolerance to iron deficiency-induced chlorosis in Arabidopsis. Plant Physiology 170, 1030-1045.

Fourcroy P, Sisó-Terraza P, Sudre D, Savirón M, Reyt G, Gaymard F, Abadía A, Abadia J, Alvarez-Fernández A, Briat JF. 2014. Involvement of the ABCG37 transporter in secretion of scopoletin and derivatives by Arabidopsis roots in response to iron deficiency. New Phytologist 201, 155-167.

Gallais A, Coque M, Quilléré I, Prioul JL, Hirel B. 2006. Modelling postsilking nitrogen fluxes in maize (Zea mays) using $15 \mathrm{~N}$-labelling field experiments. New Phytologist 172, 696-707.

Guiboileau A, Avila-Ospina L, Yoshimoto K, Soulay F, Azzopardi M Marmagne A, Lothier J, Masclaux-Daubresse C. 2013. Physiological and metabolic consequences of autophagy deficiency for the management of nitrogen and protein resources in Arabidopsis leaves depending on nitrate availability. New Phytologist 199, 683-694.

Guiboileau A, Yoshimoto K, Soulay F, Bataillé MP, Avice JC, Masclaux-Daubresse C. 2012. Autophagy machinery controls nitrogen remobilization at the whole-plant level under both limiting and ample nitrate conditions in Arabidopsis. New Phytologist 194, 732-740.

Hammond J, White P. 2008. Diagnosing phosphorus deficiency in crop plants. In: White JP, Hammond PJ, eds. The ecophysiology of plantphosphorus interactions. Dordrecht: Springer, 225-246.

Hanaoka H, Noda T, Shirano Y, Kato T, Hayashi H, Shibata D, Tabata S, Ohsumi Y. 2002. Leaf senescence and starvation-induced chlorosis are accelerated by the disruption of an Arabidopsis autophagy gene. Plant Physiology 129, 1181-1193.

Himelblau E, Amasino RM. 2001. Nutrients mobilized from leaves of Arabidopsis thaliana during leaf senescence. Journal of Plant Physiology 158, 1317-1323.
Htwe NMPS, Yuasa T, Ishibashi Y, Tanigawa H, Okuda M, Zheng S, Iwaya-inoue M. 2011. Leaf senescence of soybean at reproductive stage is associated with induction of autophagy-related genes, GmATG8c, GmATG8i and GmATG4. Plant Production Science 14, 141-147.

Ibeas MA, Grant-Grant S, Navarro N, Perez MF, Roschzttardtz H. 2017. Dynamic subcellular localization of iron during embryo development in Brassicaceae seeds. Frontiers in Plant Science 8, 2186.

Inoue Y, Suzuki T, Hattori M, Yoshimoto K, Ohsumi Y, Moriyasu Y. 2006. AtATG genes, homologs of yeast autophagy genes, are involved in constitutive autophagy in Arabidopsis root tip cells. Plant \& Cell Physiology 47, 1641-1652.

Jiang W, Struik PC, Van Keulen H, Zhao M, Jin LN, Stomph TJ. 2008. Does increased zinc uptake enhance grain zinc mass concentration in rice? Annals of Applied Biology 153, 135-147.

Kirisako T, Ichimura Y, Okada H, Kabeya Y, Mizushima N, Yoshimori T, Ohsumi M, Takao T, Noda T, Ohsumi Y. 2000. The reversible modification regulates the membrane-binding state of Apg8/Aut7 essential for autophagy and the cytoplasm to vacuole targeting pathway. Journal of Cell Biology 151, 263-276.

Kutman UB, Kutman BY, Ceylan Y, Ova EA, Cakmak I. 2012. Contributions of root uptake and remobilization to grain zinc accumulation in wheat depending on post-anthesis zinc availability and nitrogen nutrition. Plant and Soil 361, 177-187.

Lanquar V, Lelièvre F, Bolte S, et al. 2005. Mobilization of vacuolar iron by AtNRAMP3 and AtNRAMP4 is essential for seed germination on low iron. EMBO Journal 24, 4041-4051.

Lefèvre F, Fourmeau J, Pottier M, Baijot A, Cornet T, Abadía J, Álvarez-Fernández A, Boutry M. 2018. The Nicotiana tabacum ABC transporter NtPDR3 secretes O-methylated coumarins in response to iron deficiency. Journal of Experimental Botany 69, 4419-4431.

Li F, Vierstra RD. 2012. Autophagy: a multifaceted intracellular system for bulk and selective recycling. Trends in Plant Science 17, 526-537.

Li X, Zhang H, Ai Q, Liang G, Yu D. 2016. Two bHLH transcription factors, bHLH34 and bHLH104, regulate iron homeostasis in Arabidopsis thaliana. Plant Physiology 170, 2478-2493.

Liu Y, Bassham DC. 2012. Autophagy: pathways for self-eating in plant cells. Annual Review of Plant Biology 63, 215-237.

Lynch JP, Brown KM. 2008. Root strategies for phosphorus acquisition. In: White JP, Hammond PJ, eds. The ecophysiology of plant-phosphorus interactions. Dordrecht: Springer, 83-116.

Maillard A, Diquélou S, Billard V, Laîné P, Garnica M, Prudent M, Garcia-Mina JM, Yvin JC, Ourry A. 2015. Leaf mineral nutrient remobilization during leaf senescence and modulation by nutrient deficiency. Frontiers in Plant Science 6, 317

Mary V, Schnell Ramos M, Gillet C, et al. 2015. Bypassing iron storage in endodermal vacuoles rescues the iron mobilization defect in the natura resistance associated-macrophage protein3natural resistance associatedmacrophage protein4 double mutant. Plant Physiology 169, 748-759.

Masclaux-Daubresse C, Chardon F. 2011. Exploring nitrogen remobilization for seed filling using natural variation in Arabidopsis thaliana. Journal of Experimental Botany 62, 2131-2142.

Masclaux-Daubresse C, Chen Q, Havé M. 2017. Regulation of nutrient recycling via autophagy. Current Opinion in Plant Biology 39, 8-17.

Matsuura A, Tsukada M, Wada Y, Ohsumi Y. 1997. Apg1p, a nove protein kinase required for the autophagic process in Saccharomyces cerevisiae. Gene 192, 245-250.

Moore KL, Zhao FJ, Gritsch CS, Tosi P, Hawkesford MJ, McGrath SP, Shewry PR, Grovenor CRM. 2012. Localisation of iron in wheat grain using high resolution secondary ion mass spectrometry. Journal of Cereal Science 55, 183-187.

Morrissey J, Baxter IR, Lee J, Li L, Lahner B, Grotz N, Kaplan J, Salt DE, Guerinot ML. 2009. The ferroportin metal efflux proteins function in iron and cobalt homeostasis in Arabidopsis. The Plant Cell 21, 3326-3338.

Murgia I, Arosio P, Tarantino D, Soave C. 2012. Biofortification for combating 'hidden hunger' for iron. Trends in Plant Science 17, 47-55.

Nouet C, Motte P, Hanikenne M. 2011. Chloroplastic and mitochondrial metal homeostasis. Trends in Plant Science 16, 395-404.

Pottier M, García de la Torre VS, Victor C, David LC, Chalot M, Thomine S. 2015 a. Genotypic variations in the dynamics of metal concentrations in poplar leaves: a field study with a perspective on phytoremediation. Environmental Pollution 199, 73-82. 
Pottier M, Masclaux-Daubresse C, Yoshimoto K, Thomine S. 2014. Autophagy as a possible mechanism for micronutrient remobilization from leaves to seeds. Frontiers in Plant Science 5, 11.

Pottier M, Oomen R, Picco C, Giraudat J, Scholz-Starke J, Richaud P, Carpaneto A, Thomine S. 2015b. Identification of mutations allowing Natural Resistance Associated Macrophage Proteins (NRAMP) to discriminate against cadmium. The Plant Journal 83, 625-637.

Reumann S, Voitsekhovskaja O, Lillo C. 2010. From signal transduction to autophagy of plant cell organelles: lessons from yeast and mammals and plant-specific features. Protoplasma 247, 233-256.

Reyt G, Boudouf S, Boucherez J, Gaymard F, Briat JF. 2015. Ironand ferritin-dependent reactive oxygen species distribution: impact on Arabidopsis root system architecture. Molecular Plant 8, 439-453.

Robinson NJ, Procter CM, Connolly EL, Guerinot ML. 1999. A ferricchelate reductase for iron uptake from soils. Nature 397, 694-697.

Rossato L, Lainé P, Ourry A. 2001. Nitrogen storage and remobilization in Brassica napus $L$. during the growth cycle: nitrogen fluxes within the plant and changes in soluble protein patterns. Journal of Experimental Botany 52, 1655-1663.

Santi S, Schmidt W. 2009. Dissecting iron deficiency-induced proton extrusion in Arabidopsis roots. New Phytologist 183, 1072-1084.

Schuler M, Rellán-Álvarez R, Fink-Straube C, Abadía J, Bauer P. 2012. Nicotianamine functions in the phloem-based transport of iron to sink organs, in pollen development and pollen tube growth in Arabidopsis. The Plant Cell 24, 2380-2400.

Shi R, Weber G, Köster J, Reza-Hajirezaei M, Zou C, Zhang F, von Wirén N. 2012. Senescence-induced iron mobilization in source leaves of barley (Hordeum vulgare) plants. New Phytologist 195, 372-383.

Shingles R, North M, McCarty RE. 2002. Ferrous ion transport across chloroplast inner envelope membranes. Plant Physiology 128, 1022-1030.

Stacey MG, Patel A, McClain WE, Mathieu M, Remley M, Rogers EE, Gassmann W, Blevins DG, Stacey G. 2008. The Arabidopsis AtOPT3 protein functions in metal homeostasis and movement of iron to developing seeds. Plant Physiology 146, 589-601.
Thompson AR, Doelling JH, Suttangkakul A, Vierstra RD. 2005. Autophagic nutrient recycling in Arabidopsis directed by the ATG8 and ATG12 conjugation pathways. Plant Physiology 138, 2097-2110.

van der Graaff E, Schwacke R, Schneider A, Desimone M, Flügge UI, Kunze R. 2006. Transcription analysis of Arabidopsis membrane transporters and hormone pathways during developmental and induced leaf senescence. Plant Physiology 141, 776-792.

Velu G, Ortiz-Monasterio I, Cakmak I, Hao Y, Singh RP. 2014. Biofortification strategies to increase grain zinc and iron concentrations in wheat. Journal of Cereal Science 59, 365-372.

Vert G, Grotz N, Dédaldéchamp F, Gaymard F, Guerinot ML, Briat JF, Curie C. 2002. IRT1, an Arabidopsis transporter essential for iron uptake from the soil and for plant growth. The Plant Cell 14, 1223-1233.

Waters BM, Grusak MA. 2008. Whole-plant mineral partitioning throughout the life cycle in Arabidopsis thaliana ecotypes Columbia, Landsberg erecta, Cape Verde Islands, and the mutant line $y s / 1 y s / 3$. New Phytologist 177, 389-405.

WHO. 2016. Iron deficiency anaemia. Geneva: World Health Organization.

Wildermuth MC, Dewdney J, Wu G, Ausubel FM. 2001. Isochorismate synthase is required to synthesize salicylic acid for plant defence. Nature 414, 562-565.

Xiong Y, Contento AL, Bassham DC. 2005. AtATG18a is required for the formation of autophagosomes during nutrient stress and senescence in Arabidopsis thaliana. The Plant Journal 42, 535-546.

Yoshimoto K. 2012. Beginning to understand autophagy, an intracellular self-degradation system in plants. Plant \& Cell Physiology 53, 1355-1365.

Yoshimoto K, Hanaoka H, Sato S, Kato T, Tabata S, Noda T, Ohsumi Y. 2004. Processing of ATG8s, ubiquitin-like proteins, and their deconjugation by ATG4s are essential for plant autophagy. The Plant Cell 16, 2967-2983.

Yoshimoto K, Jikumaru Y, Kamiya Y, Kusano M, Consonni C, Panstruga R, Ohsumi Y, hirasu K. 2009. Autophagy negatively regulates cell death by controlling NPR1-dependent salicylic acid signaling during senescence and the innate immune response in Arabidopsis. The Plant Cell 21, 2914-2927. 